\title{
Reliable and efficient data dissemination scheme in VANET: a review
}

\author{
Sami Abduljabbar Rashid ${ }^{1}$, Lukman Audah ${ }^{2}$, Mustafa Maad Hamdi ${ }^{3}$, \\ Mohammed Salah Abood ${ }^{4}$, Sameer Alani ${ }^{5}$ \\ ${ }^{1,2,3}$ Faculty of Electrical and Electronic Engineering, Universiti Tun Hussein Onn Malaysia, Malaysia \\ ${ }^{3}$ Department of Computer Engineering Technology, Al-Maarif University College, Iraq \\ ${ }^{4}$ Faculty of Information and Electronics Engineering, Beijing Institute of Technology, China \\ ${ }^{5}$ Centre for Advanced Computing Technolgy (C-ACT), Faculty of Information and Communication Technology, \\ Universiti Teknikal Malaysia Melaka, Malaysia
}

\begin{tabular}{l} 
Article Info \\
\hline Article history: \\
Received Mar 12, 202 \\
Revised May 30, 2020 \\
Accepted Jun 16, 20 \\
\hline Keywords: \\
Data dissemination \\
QoS \\
Routing protocols \\
VANET
\end{tabular}

\begin{abstract}
Vehicular ad-hoc network (VANET), identified as a mobile ad hoc network MANETs with several added constraints. Basically, in VANETs, the network is established on the fly based on the availability of vehicles on roads and supporting infrastructures along the roads, such as base stations. Vehicles and road-side infrastructures are required to provide communication facilities, particularly when enough vehicles are not available on the roads for effective communication. VANETs are crucial for providing a wide range of safety and non-safety applications to road users. However, the specific fundamental problem in VANET is the challenge of creating effective communication between two fast-moving vehicles. Therefore, message routing is an issue for many safety and non-safety of VANETs applications. The challenge in designing a robust but reliable message dissemination technique is primarily due to the stringent QoS requirements of the VANETs safety applications. This paper investigated various methods and conducted literature on an idea to develop a model for efficient and reliable message dissemination routing techniques in VANET.
\end{abstract}

Copyright (c) 2020 Institute of Advanced Engineering and Science. All rights reserved.

\section{Corresponding Author:}

Lukman Audah,

Faculty of Electrical and Electronic Engineering,

Universiti Tun Hussein Onn Malaysia,

86400 Parit Raja, Batu Pahat, Johor, Malaysia.

Email: hanif@uthm.edu.my

\section{INTRODUCTION}

This introductory chapter presents an overview of the complete work presented where the introduction to the vehicular ad-hoc network (VANET) is discussed as an integral part of an ITS. This is a detailed description of work done in the past on the data message routing that leads this work to formulate a problem followed by the possible solution. Further discussion is made towards the proposed approach and scope of this work, followed by future plans. Vehicular ad-hoc network (VANET) has been identified as one of the components for intelligent transportation systems (ITS) [1].

VANET is a type of network that is established on the fly based on the availability of vehicles on roads and supporting infrastructures along the roads, such as base stations. These road-side infrastructures are required to provide a communication facility, particularly when enough vehicles are not available on the roads for effective communication. Hence, the nodes in VANET may now include vehicles on roads or road-side units, which their mode of communication may be in vehicle-to-vehicle and vehicle-toinfrastructure. On the other side, intelligent transportation systems have offered a wide range of ITS applications. However, the specific fundamental problem in VANET is that chance for effective 
communication between two fast-moving vehicles is only available at the time when a stable link is established between them, but this has happened only in a few seconds [2, 3]. Therefore, message routing is a problem for many safety and non-safety of ITS applications. The challenge in designing a robust but reliable message dissemination technique is primarily due to the stringent QoS requirements of the ITS safety applications [4].

\section{QUALITY OF SERVICE (QOS) IN VANET}

QoS assistance helps to enhance networking activity and allow it easier and properly coordinate knowledge exchanged across the network and to increase network efficiency. The concept of QoS is a network arrangement or guarantee to provide the customer with a variety of quantifiable pre-specified service functionality including network latency, latency variances, usable capacity, packet loss (loss rate), etc. etc. The IETF RFC 2386 defines QoS as a collection of connection specifications that the network should satisfy for a packet stream from source to destination [5]. The capacity of the network to provide unique QoS is dependent on the network's properties, which extend throughout the critical elements of the network.

The property included contact latency, transfer, failure levels, and error rate for the transfer relation. Of the nodes, hardware characteristics provide operating speed and storage capacity. In addition to physical node characteristics and communication relations, QoS control algorithms that operate at different network levels often help QoS in networks. Regrettably, the features of MANETs show weak support for QoS [6, 7]. The actual transmitting power with comparably small errors and the failure rate is weak and time-varying. Other potential wireless devices that nodes may use at the same time to connect MANETs [8, 9]. In order to support QoS, each technology requires a MAC layer protocol. The QoS structures around the MAC framework would also be readily matched to the different simple wireless technologies. It will be a task to encourage various standard standards of service in a continuously diverse setting. The stochastic trait of communications quality in a MANET allows it difficult for a system to obtain guarantees [10-12].

\section{ISSUES AND PROBLEM IN DATA DISSEMINATION}

Vehicle networks can have two types of implementation: the first, using pure ad hoc communications, and the other, using infrastructure to allow communications. These types of networks pose new and demanding challenges, mainly in the case of the absence of infrastructure, speed, and topographic conditions in which the nodes are mobilized. In extra to the above, conventional routing protocols cannot be applied to this type of networks in the same way as in conventional networks, since they are not prepared to adapt to the variable conditions that may arise in the environment in which they are used. They play vehicular networks. On the other side, considerations of security and quality of service arise that must be adapted to the conditions of this type of network [13, 14].

Unlike traditional wired networks, in an ad-hoc wireless network, each of the nodes works simultaneously as a station and as a router. For each node to be able to communicate with the rest, it is necessary to maintain information of the network to which it belongs and have an algorithm that governs the sending and receiving of packages. The routing protocol is defined as a set that forms the routing algorithm and the information about the conditions of the network. The protocols of routing in ad hoc networks must adapt quickly and correctly to frequent and unpredictable changes in the topology of the network, making minimum use of memory, transmission power and bandwidth [15, 16]. The routing process is defined as the act of transmitting information from one source to a destination source, that is, node to node. A routing process is considered as the selection of paths from a source to a destination within a network. A routing protocol for ad-hoc networks allows the network to be fully organized on its own, and its main objective is the correct and efficient establishment of routes between a pair of nodes. Messages are delivered correctly and timely [17].

The construction of routes must occur with a minimum overload in the headers of the control packets and minimum consumption of bandwidth. There are many routing protocols have been proposed in order to cover the different needs depending on the different environments and traffic conditions. The great variety of existing protocols means that there are several criteria for their classification, which in turn reflect the most important aspects considered for their design. The planning criterion assumes the classification most widely used in the literature and attends to the moment in which the route is calculated from one source node to another source (destination node). While in the proactive protocols, the updated information is kept at all times, in the reagents, the route to the destination is searched when the need to establish a communication arises. At the end of any vehicular communication network, the following questions need to be answered prior to design an efficient and reliable message dissemination scheme in VANET for QoS of intelligent transportation system implementation. 
- What method of optimization can be effectively deployed to provide a stable link between any two communicating nodes in VANET?

- How to build a reliable and efficient route/path for connecting a sender node and a receiver node and suitable for QoS routing in VANET?

- What performance parameters shall be used such that QoS of the ITS application is acceptable?

In order to solve the above questions, the hypothesis can be made is that if a stable link can be established between any two communicating nodes in VANET (V2V or V2I), there is a great chance that a reliable and an efficient messages dissemination/routing can be made in the network to support the QoS achievement for the ITS implementation.

\section{ROUTING IN VANET}

Based on the routing protocol, communication between mobile nodes may be single-hop or multi-hop in VANET. The routing protocol also decides the end-to-end path between source nodes and destination nodes. Low latency and the dependable end to end data delivery are the two main factors for efficient routing protocols. However, route maintenance, route discovery, and sudden changes in the topology are the key factors in designing efficient routing protocols [18, 19]. Numerous routing protocols have been proposed in the literature to provide reliable and efficient routing in VANET. These can be classified as shown in Figure 1.
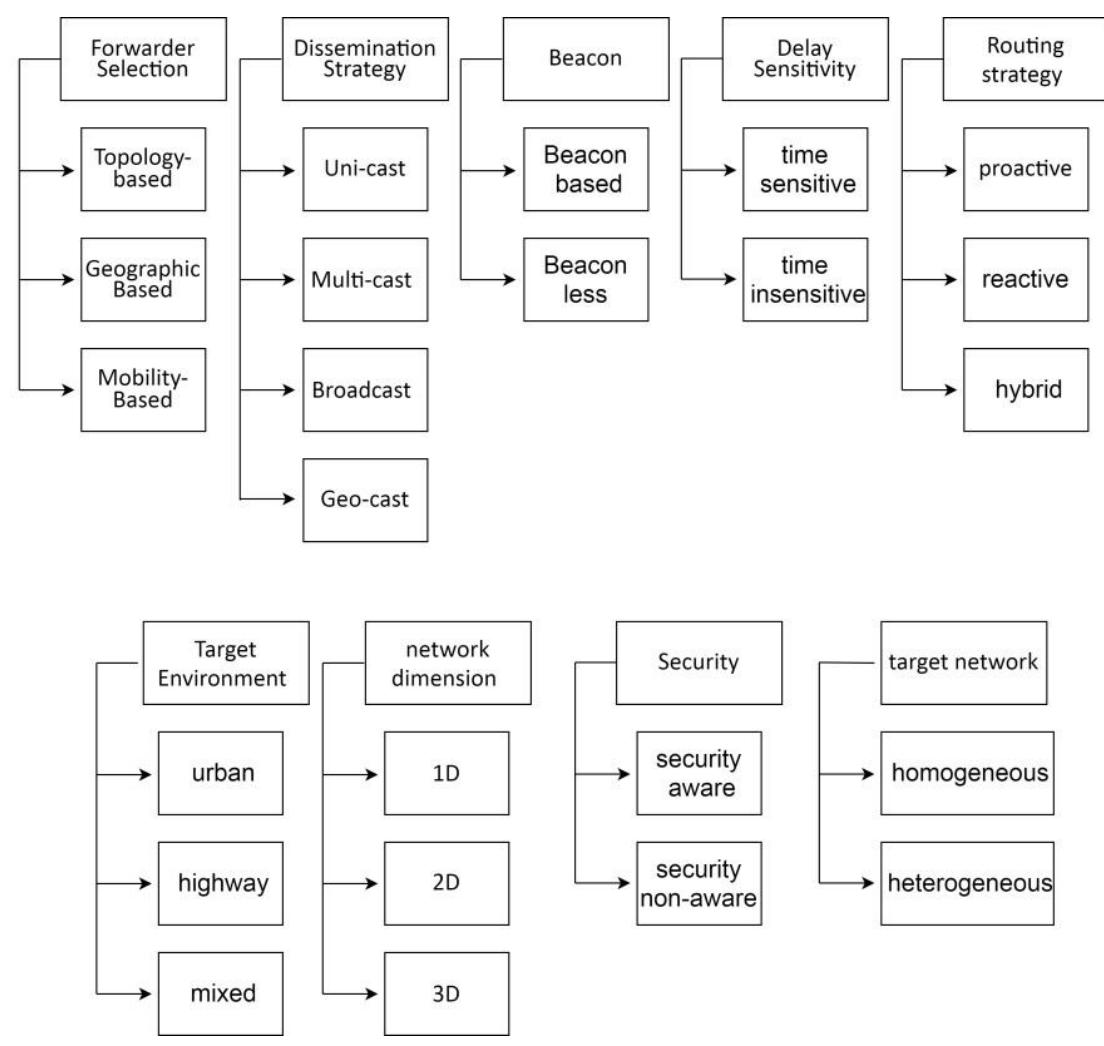

Figure 1. Types of routing protocols

\section{ALGORITHM BASED ROUTING IN VANETS}

The development of routing protocols in VANET was based on various models and approaches. Some of them are regarded as famous models in the literature in various applications. We present here some of them. Various researchers have developed routing protocols for VANETs based on meta-heuristic optimization models. Some researchers have adopted multi-objective optimization for this purpose and used it to optimize existing routing protocols and to make it more suitable for VANETs. In the work of [20], the firefly was used as multi-objective optimization for OLSR for VANET based on a developed framework. More specifically, the framework consists of three stages: 1-generating the scenarios for creating the network road and the traffic, 2- formulating the weighted cost function and 3- optimizing the protocol 
parameters using considered parameters related to the time of holding the message, the refresh time of the link status, and hello message etc. However, the evaluation has not generated the MOO evaluation measures the number of non-dominated solutions, hyper-volume, set coverage, ... etc.

The literature contains a significant amount of works using meta-heuristic approaches for optimization of the VANET network in its different layers. In the context of applying meta-heuristic for optimization of MAC layer in VANET [21], a MOO framework for optimization of MAC and the physical layer was proposed. The framework aims at the optimization of three objectives: throughput, packet loss, and latency. The solution is proposed to include various parameters in the protocol of the two layers. For optimization, the framework was evaluated based on the non-dominated sorting genetic algorithm NSGA-II. The work of [22] has proposed using a genetic whale optimization algorithm for assisting in selecting a root channel for transmission. The protocol was named as a modified cognitive tree routing protocol MCTRP. The protocol can be categorized under effective channel utilization in VANET. Another aspect of applications of meta-heuristic optimization in VANET is controlling data dissemination and preventing broadcast storms. In the work of [23], the authors have aimed at optimizing link stability and lifetime as well as minimizing the number of obstacles within the selected route. The optimization function was formulated as a single objective function with including the two terms. Next, the approach has used discrete particle swarm optimization.

A complexity analysis has proved the feasibility of the method in real-world applications. Some researchers have proposed meta-heuristic based optimization for establishing multi-cast-based routing in VANETs. An improved shuffled frog-leaping algorithm-based [24] QoS constrained multicast routing (ISFLABMR) was proposed. The goal is to find the optimal sub-tree for message dissemination. This sub-tree is the optimal multi-cast tree from available options of the multi-cast tree between the source and the destination. The formulation of the fitness function has aimed at optimizing various QoS parameters, more specifically, jitter, latency, and bandwidth, in order to reduce the transmission cost of multi-cast routing. Apart from that, some papers have focused on meta-heuristic based VANET security, such as the work of [25], where swarm algorithms of artificial intelligence were proposed for countering routing attacks.

The literature of VANETs routing protocols included many techniques based on meta-heuristic approaches. In the work of [26], an approach of selecting routes based on their fitness values is proposed using genetic. The routes were found using a greedy approach, and then the best route was selected based on genetic. After proving the superiority of the approach over other benchmarking routing protocols, the author stated that the algorithm suffers from slow computation, and its combination with heuristic can increase the performance of the algorithm. This concern of speed of genetic algorithm was indicated by other authors such as [27] in their work where genetic was applied in both serial and parallel ways, and they proved the superiority of a similar way when using multi-core architecture. Other researchers have developed metrics for route optimization. The metrics include information about signal strength, path loss, transmit power and frequency such as the work of [28], in addition to the new metrics, an improved genetic-based routing algorithm was proposed. The approach uses a non-probabilistic selection approach using k-means clustering. The author also has stated about the real-time concern and regarded it as a future investigation. It is observed in the literature that significant amount of meta-heuristic based routing has focused on the problem of multi-cast routing and its result on the congestion in the network.

An example is a work of [29], where a micro-artificial bee colony was used for multi-cast routing. The algorithm is proposed for achieving QoS-constrained VANET with maximizing network lifetime and minimizing delay cost. The solution of the algorithm proposes a bit-based encoding for the route between the source and the destination inside a spanning tree. The algorithm also proposed incorporating an energy model that is suitable for electrical efficiency. On the other side, the optimization considers only a small part of the population, which makes it more computationally efficient. A similar work for developing meta-heuristic based multi-cast routing is the work of [30] where firefly was improved by using Levey distribution, and bit string coding was proposed for searching for the path that achieves the best cost which is represented by minimizing the energy consumption and E2E delay using a single objective function.

\section{DATA DISSEMINATION IN VANET}

The data dissemination is a crucial part of VANET for various applications, particularly related to safety, to alert the drivers about the traffic incidents in their local region. An example of data dissemination in VANET is shown in Figure 2. Although VANET inherits many concepts from traditional mobile ad hoc networks (MANET), VANET is defined by its high mobility and frequent disconnection, and data dissemination is an integral part of the network. This key difference is the reason for VANET that traditional MANET routing data dissemination methods like AODV and DSR are not applicable in it. Unsurprisingly 
many techniques of data dissemination have already been proposed for VANET. These techniques can be distinguished into different categories as being Unicast [31], Multicast [32], or Broadcast. The techniques of data dissemination in VANET can also be distinguished as one relying on the existence of an infrastructure [33] and another one relying on zero infrastructure support [34]. For the intent of this study, the techniques of data dissemination in VANET have been classified into two categories: (1) Those Techniques which presume the existence of end-to-end connectivity between vehicles. (2) Those Techniques do consider the lack of connectivity between vehicles. Techniques like VGrid, MURU [35], and PBR [36] are the example of the first category.

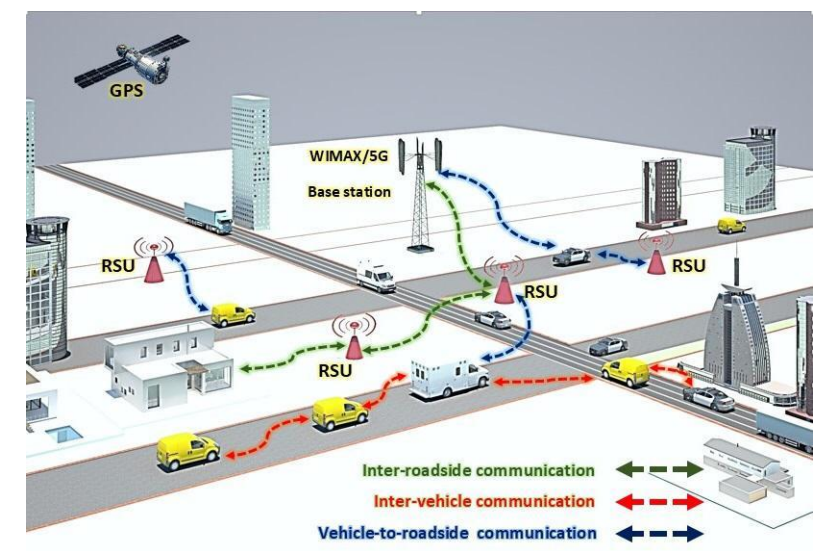

Figure 2. Data dissemination in a VANET

The VGrid Data dissemination technique is a position-based, on-demand routing protocol that creates a path from a static source node to the vehicles present in a destination area. Another technique is MURU. It is a multi-hop routing protocol proposed for discovering strong routes in urban VANET. MURU aims to reduce the probability of path-breaking by using movement data of all vehicles and by using a unique parameter stated as expected disconnection degree factor to choose the utmost strong route from source to destination [37]. MURU prudently assumes that there will be several routes between destination and source and its aim to choose the one that is highly established. Position-based routing (PBR) protocol is used where packet forwarding decisions are taken based on power awareness. Connectivity-aware routing (CAR) was proposed for the uncertain end-end to connectivity in VANET. The fundamental concept of CAR is to find out the connection route between the destination and source. It does not matter whether the route is the shortest one or not; this is accomplished by using a path detection process before the actual data can be sent.

Moreover, this is because a longer entirely connected path is better than the shortest path, which may further experience the connectivity issue at some point. Directional propagation protocol (DPP) [38, 39] makes use of the directional pattern of the vehicles and data to disseminate the packet. DPP demonstrates real traffic situations where vehicles form groups on the road, and these groups might get detached from each other. Furthermore, a real traffic situation reflects in research where detached vehicles might make a cluster with each other. A hybrid routing protocol is also presented, where packets can be directed inside the cluster, but to associate these clusters, it depends on a prior infrastructure. Even though the real traffic conditions are reflected in the hybrid routing protocol, its dependence on pre-existing. The major disadvantage of all existing techniques of data dissemination is that either they do not take account of frequent VANET disconnection such as VGrid, MURU and PBR or techniques that take account of disconnections, these techniques have to go through many disadvantages such as routing loops and wasting the limited resources by sending redundant messages in their data dissemination.

\subsection{Quality of service (QoS)-based data dissemination}

In VANETs, some of the applications are delay-sensitive. We have other efficiency criteria, such as applications relevant to health. Therefore, an adequate data distribution service consistency (QoS) program needs to be developed to guarantee the transmission of data. Wahab [40] proposed a new QoS system management protocol transmission that can route a packet as soon as possible from the source node to the destination. Throughout this protocol, a new metric is created to allow various weights for the routing path between nodes, from which algorithms to build and maintain routes are established. This protocol can overcome a storm and easily recover if a connection fails. This protocol can solve through consideration of 
one compromise between QoS requirements and strong versatility restrictions, Waheb et al., introduced a new QoS clustering algorithm [41]. The proposed algorithm was developed to shape and sustain stable clusters while meeting QoS requirements.

\subsection{Delay-based data dissemination}

The delayed data distribution approaches have been established to cope efficiently with the diffusion problem. Such solutions rely on nodes used to pick a relay node for forwarding data packets. UGAD [42] uses a responsive pause algorithm for suppressing broadcast in city VANETs. At intersections, the UGAD lets vehicles retransmit easily by setting priority preferences. Furthermore, cars run two separate kinds of control mechanisms to satisfy the need for transport.

As a consequence, the packet arrival ratio is increased while the redundant transmission is reduced. A comprehensive method for deciding specific vehicle objectives according to the delay criterion. TVBR [43] proposes a timer-based vehicle backend network protocol in which each node takes distribution decisions only through information stored in the header, its current state, and local calculations. This protocol uses node times to select a relay node to forward the packet. However, if the protocol is not correctly configured, the time quantity impact will lead to the dissemination stop. In [43], when evaluating data dissemination, an assessment model is proposed in order to characterize the actions of incorrect forwarding systems. The results obtained from several simulations help gain insights into the false transmitting issue that affects the use of VANET-based networking protocols. The suggested model is used to determine the proper dimensioning of the message flow admission control and pacing control processes, thereby limiting network charges to an acceptable data rate point.

\subsection{Probability-based data dissemination}

Probability dependent schemes allow receivers to forward packets that are likely to reduce the reliability of the information. Wisitpongphan [44] and Tonguz [45] propose two probability-based, weighted-p-and slotted-p-based, cross-hop transmission protocols. The other node transmits the packet with a higher likelihood under the Weighted-p Protocol. However, following the gap in this procedure, the chance of forwarding decreases. Therefore, the enhanced intensity would contribute to more inefficient contact and a hurricane. The future forwarding region is split into many sections of the Slotted-1 Protocol, with different waiting times. The node that is further from the sender will wait for less time. However, since the traffic movement varies over time, it is hard to assess correctly the number of time slots that should be separated. Panichpapiboon [46] expands the concept of a system for probabilistic broadcasting. The likelihood of re-transmission is calculated by the spatial function of the inter-vehicle delivery, which enables the IF system to minimize the amount of duplicate re-transmissions efficiently. Therefore, the IF principle can be extended for every inter-vehicle separation distribution. Mostafa [47] presents a modern, efficient, and low-collision packet-forwarding system focused on probabilistic re-transmissions for VANETs. It operates in a distributed way where every node retransmits a packet with a pre-defined probability. The likelihood is calculated by many parameters, including the node number, the inter-vehicle gap between the nodes, and the next-hop propagation path.

\subsection{Push-based data dissemination}

The push-based distribution of data is suitable for some programs that promote local and public interest data. This scheme can create low containments during data transmission and collisions. Schwartz [31] suggests a protocol to disseminate push-based results. When utilizing an efficient distributed deletion strategy, the diffusion tempest issue with dense density may be minimized throughout the network. It can effectively control the disconnected network, based on the Carry-and-Future communication strategy. The newness and robustness of the current procedure are part of the new definition. However, in a dense environment, the power control system does not significantly reduce the network load. Mondal [48] proposed to guarantee secure and effective data transfer with one relative position-based data distribution system. The relative position-based addressing method is configured initially to define the planned receivers efficiently. A one-way broadcast protocol will then be proposed to make a set of candidate's nodes store messages to improve the packet delivery rations and to reduce packet delivery delays. Nevertheless, this paper has not addressed the problems of intrusion, scalability, and accessibility.

\subsection{Pull-based data dissemination}

For personal or private details, pull-based data distribution is most suitable, where vehicles can request data information explicitly. Bai [49] Proposes a unicast-based data distribution architecture on-demand for VANETs. The system will scatter data as response messages if any question messages are issued. The real automobiles that just disseminate data are observed. This scheme, however, will increase 
the overhead calculation. Lakas [50] presented a capable and fast transmittal device for vital security messages. The key to VMP is that it defines several trustworthy transmitters with differentiated delays and utilizes the cooperative transmission mechanism to support the transmission of the data. It needs, however, cross-cutting. A peer to peer VANET application is proposed in [51] to track and avoid obstruction in public transport and to share details on public traffic. The application uses a push-based geo-cast system to collect and disseminate information efficiently. The program will raise the amount of knowledge shared between vehicles by incorporating a caching scheme.

\subsection{Cluster-based data dissemination}

In order to deal with some issues and challenges caused by the particular characteristics of VANETs, most of the proposed solutions are to self-organize the vehicular network by creating dynamic clusters. Singh [52] proposed one protocol for multiple target regions for complex and dispersed distribution of information. This procedure comprises two primary components: configuration of geocasting and management of geocasting. The former uses route connecting and main points to minimize the overall period for transmitting the word. Lastly, the concept of regional autonomy divides each region into many small areas in order to decrease the redundancy of information and dynamic maintenance costs. The suggested procedure will minimize the probability of the same message and avoid the loss of valuable data. An algorithm for VANETs is suggested for hybrid backbone-based clusters [53]. The algorithm creates cluster heads and chooses them, taking into consideration the number of links and versatility for vehicles. In the context of the growth of a cluster, nodes with reasonably large communication initially create a backbone called a leadership. The leadership then takes part in unit heads and company reorganization depending on the relative average pace of vehicles. In [54], a VANET mobile clustering scheme is suggested to shape clusters that are spread using the Affinity Propagation algorithm. Their clustering algorithm takes into consideration several variables, such as their average cluster head time, their average participant time, the average rate of cluster-head shifts, and the total number of network clusters.

In [55], VANET's was introduced for a modern cluster-based emergency data transparency system. First, the weight value for each node is calculated by taking into account different metrics. The cluster head was chosen for the node with the minimum weight value. Cluster preparation and repair systems will be provided. Recently, several techniques and algorithms have been proposed. A study was presented in [45]. The proposed method was focused on the design and delivery of a new Distributed protocol for the deployment of multi-hop engines. The system was supposed to function in all traffic schemes, including Dense and sparse extreme scenarios Traffic systems. DV-CAST is a distributed transmission protocol that only utilizes knowledge from local topology to handle VANET messages. Quality of this is seen in terms of precision, usefulness, and scalability. The current DV-CAST Protocol is outstanding. In another work [46], the definition of IF is extended to be specific to any distance distribution of the intervehicle. In this study, each vehicle should rebroadcast the received information from the network. However, this mechanism would lead to a useless occupation of the radio channel and would minimize redundancy. While in [47], the researchers have introduced a new reliable, low-collision vehicle ad hoc network packet forwarding system based on a radio diffusion probabilistic. The collision-aware reliable forwarding scheme (CAREFOR) was proposed to work in a distributed network form as each car receiving a packet would resend this packet to pre-defined likelihood. This opportunity was exploited by various physical influences, such as the density of the vehicles in the region, extracted from the vehicle environment vehicle transfer and reception, and, eventually, the next-hop transmission system. However, the convergence of all these variables into one probability enabled each driver to determine that a new automobile will accept this message, which will be possible whether the message is returned.

The study of [31] provided a reliable and straightforward mechanism for the transmission of data in crowded and space-saving vehicle networks. The simulation findings revealed that the proposed protocol improved the transmission ratio and improved robustness in various path conditions compared with DV-CAST. [48] Proposed a new scheme to efficiently disseminate the message (RPB-MD) dependent on the relative location and disseminate vehicle communications in the field of interest effectively. The RPB method model was suggested to describe the relative position based on Desired zone-of-relevance receivers accurately. To guarantee a strong coverage level and Low distribution time, DGBR was implemented to have a spatial greedy transmission routing. The message of high reliability is carried in the nominee nodes community. Besides, to ensure performance, the time parameters of the protocol are tailored to a document wide distribution of road characteristics and cars. The feasibility of the protocol was analyzed to show the strength and confidence of RPB-MD. The findings of the simulations revealed that RPB-MD could manage a strong output level, minimal overhead relative to current representative structures, reasonable pause, and fast reliability of the network under specific vehicle densities and transmitting rate of data. Bai [49] proposed a crucial function in road safety, detection of traffic accidents, and reduction of traffic 
congestion by disseminating messages among vehicles. The periodic broadcasting was indicated as an efficient approach to serve the requests of many vehicles without selecting any route between source and destination. In [50] a study was presented a robust program for the rapid diffusion of safety communication through critical space, known as vehicle multi-hop broadcasting protocol (VMP), through lowering the endto-end latency and re-transmission ratio while retaining high message arrival speeds, the VMP demonstrated improved results than previous contested systems.

In [51] proposed a VANET technology peer-to-peer exchange of knowledge on highways, allowing vehicles to identify and mitigate traffic congestion. Amid caching, they have shown that. The quality of gathered traffic information was maintained, and similar data were achieved for the average decrease of congested road travel. Another study was presented in [52]. The researchers suggested the knowledge sharing system SmartGeocast for many target areas, with two protocols, namely the configuration of geocasting and the management of geocasting. The suggested SmartGeocast protocol demonstrated that the risk of obtaining repetitive messages could be minimized when attempting to minimize the loss of essential details. Moreover, a clustering algorithm focused upon hybrid backbone is suggested for VANETs. The definition of the number of links and versatility of vehicles is used for clusters and the collection of clusters. The findings of simulation have shown similar cluster stability in metropolitan environments in the proposedalgorithm. [53].

Another article proposed a modern, intelligent transmission-based secure and effective data distribution method, with a goal to resolve recurrent disconnection problems during data delivery. A detailed network and traffic analysis for different metrics, such as latency, packet transmission ratio and efficiency. The suggested densely variable approach increases average PDR and performance by 31.50 percent and 25.30 percent, respectively, relative to state-of-the-art protocols [54]. A new hybrid was proposed in [55]. The proposed technique was namely new hybrid relay class Selection of nodes in which the strongest aspects of current communication protocols are used optimized accessibility terminology, contact times, and use of bandwidth minimizing their vulnerabilities. The findings of this working study indicated that the current hybrid solution improved reachability by up to $10 \%$ relative to standard models, which are more successful. This progress is accomplished because there is a small reduction in contact times and messages saved re-transmission ratios. The study of [56] intended to refine the method of discovery of suitable paths for the effective distribution of data in VANETs, including the Encoding and Decoding phases. The method suggested protects the stability and the likelihood of obstacles event as objective using Euclidean distance in the polar coordination framework. Extensive models are used for performance measurement strategy, such as packet distribution partnership, total overhead routing. The findings indicated that the suggested algorithm was in the current literature greater than other associated structures.

In [57], the author proposed a technique of transmission utilizing a time-barrier method to eliminate communications that may disrupt the network. The presented approach was focused on the idea that a supernode should be used to disperse the message rapidly. To avoid unwanted propagation, which can also trigger the issue of the transmitted hurricane, the time barrier methods are modified in order to resolve the problem. While in [58], a modern, efficient clustering simulation versatility (MPECS) system was proposed. The basic concept of MPECS was to split the whole region into separate areas by the Voronoi graph; in order to enable each vehicle to estimate its lifetime and cost of becoming the cluster head in its current location. The proposed technique has shown evidence of significant MPECS capabilities enhance clustering design reliability with reduced overhead, finally, in [59]. This study suggested a modern scheme of data distribution focused on clustering and CBD. A classification algorithm was initially introduced by driving Vehicle directions utilizing which vehicles may cluster their data with enough contact time. The simulation indicated that the new CPB configuration had improved the performance of the systems regarding knowledge distribution, total communication duration, and the transmission ratio of packets. Table 1 summarizes recent studies (see Appendix).

\section{CONCLUSION}

This paper has presented a literature review on various VANET techniques, their routing protocols, security measures, and quality of services. Based on the literature conducted, the future development to be done in this research has also been initially proposed that will include analysis, designing, and modeling of a technique of stable link for message dissemination followed by the proposal to develop a modeled message dissemination technique. In this research, studies on various factors that influence the incident detection and monitoring based on the literature have been conducted. This review paper discusses the introduction, motivation, problem formulation, objectives, and scope of the work and significance of this work. The paper also includes a comprehensive literature review conducted in the field. 


\section{APPENDIX}

Comparison of data dissemination schemes.

Table 1. Comparison of data dissemination protocols

\begin{tabular}{|c|c|c|c|c|c|}
\hline Characteristic & Features & Map & Simulation & Advantage & Study \\
\hline $\begin{array}{l}\text { Manage the storm } \\
\text { and network link } \\
\text { issue }\end{array}$ & $\begin{array}{l}\text { Work in all transport } \\
\text { environments, detecting } \\
\text { neighborhoods, removing } \\
\text { broadcast and forwarding } \\
\text { of stores }\end{array}$ & Highway & NS2 & $\begin{array}{l}\text { Powerful against various kinds of } \\
\text { conditions of vehicle traffic, very } \\
\text { scalable and stable especially in } \\
\text { dense traffic, strong network } \\
\text { connectivity }\end{array}$ & $\begin{array}{l}\text { Tonguz et al. } \\
2010[45]\end{array}$ \\
\hline $\begin{array}{l}\text { Redundancies will be } \\
\text { minimized thus } \\
\text { maintaining } \\
\text { transparency }\end{array}$ & $\begin{array}{l}\text { Generalize the reckless } \\
\text { travel definition }\end{array}$ & Highway & Matlab & Redundancy package cap & $\begin{array}{l}\text { Panichpapiboo } \\
\mathrm{n} \text { and Chen } \\
2013[46]\end{array}$ \\
\hline $\begin{array}{l}\text { Provide a robust low- } \\
\text { collision transport } \\
\text { network }\end{array}$ & Job dispersed function & Highway & Java & $\begin{array}{l}\text { Performance in small re- } \\
\text { transmission numbers }\end{array}$ & $\begin{array}{l}\text { Mostafa et al . } \\
2014[47]\end{array}$ \\
\hline $\begin{array}{l}\text { Prevent the question } \\
\text { of transmission }\end{array}$ & Distribution of spatial data & Highway & OMNeT++ & $\begin{array}{l}\text { Small backup, no overly large } \\
\text { load Higher output volume }\end{array}$ & $\begin{array}{l}\text { Schwartz et al. } \\
2011[31]\end{array}$ \\
\hline $\begin{array}{l}\text { Reduce interruption } \\
\text { in contact }\end{array}$ & $\begin{array}{l}\text { Dissemination of related } \\
\text { position-based message }\end{array}$ & Highway & NS2 & $\begin{array}{l}\text { Robust and secure, good } \\
\text { availability, appropriate overhead } \\
\text { connectivity, strong network } \\
\text { usability }\end{array}$ & $\begin{array}{l}\text { Liu and } \\
\text { Chigan } 2012 \\
{[48]}\end{array}$ \\
\hline $\begin{array}{l}\text { Avoid channel } \\
\text { obstruction, escape } \\
\text { diffusion wind, solve } \\
\text { secret terminal } \\
\text { problem. }\end{array}$ & $\begin{array}{l}\text { Hierarchy: Root approval } \\
\text { agency, intermediate base } \\
\text { stations, leaf stage } \\
\text { vehicles }\end{array}$ & Highway & $\begin{array}{l}\text { Processing } \\
\text { Units }\end{array}$ & $\begin{array}{l}\text { Higher operation block and mean } \\
\text { answer time, higher efficiency }\end{array}$ & $\begin{array}{l}\text { Mondal and } \\
\text { Mitra } 2016 \\
\text { [49] }\end{array}$ \\
\hline $\begin{array}{l}\text { Prevent loss of } \\
\text { packets and address } \\
\text { storm diffusion } \\
\text { problem }\end{array}$ & $\begin{array}{l}\text { Designation of multiple } \\
\text { sponsoring candidate }\end{array}$ & Highway & Qualnet & $\begin{array}{l}\text { Great availability, small channel } \\
\text { expense }\end{array}$ & $\begin{array}{l}\text { Bai et al. } 2009 \\
{[50]}\end{array}$ \\
\hline $\begin{array}{l}\text { Detect and prevent } \\
\text { road haulage }\end{array}$ & $\begin{array}{l}\text { Geo-cast protocol based } \\
\text { on Pull, determines the } \\
\text { optimal routes proactively }\end{array}$ & Urban & RISIM & $\begin{array}{l}\text { Reduce the amount and reaction } \\
\text { time of transmission }\end{array}$ & $\begin{array}{l}\text { Lakas Shafqa } \\
2011[51]\end{array}$ \\
\hline $\begin{array}{l}\text { Reduce the expense } \\
\text { of communications } \\
\text { and servicing }\end{array}$ & $\begin{array}{l}\text { Dynamic transmission and } \\
\text { delivery of suspicious } \\
\text { information }\end{array}$ & Urban & NS2 & $\begin{array}{l}\text { Reduced traffic and data diffusion } \\
\text { period, ratio and efficiency } \\
\text { improvement in data receipt }\end{array}$ & $\begin{array}{l}\text { Zhang et al. } \\
2013 \text { [52] }\end{array}$ \\
\hline $\begin{array}{l}\text { Coordinate } \\
\text { coordination between } \\
\text { nodes, help to } \\
\text { enhance } \\
\text { collaboration and } \\
\text { eradicate the issue of } \\
\text { secret terminals }\end{array}$ & $\begin{array}{l}\text { Cluster formation and } \\
\text { cluster head selection }\end{array}$ & Urban & NS2 & $\begin{array}{l}\text { Reduce latency and connectivity } \\
\text { expenses and improve network } \\
\text { reliability }\end{array}$ & $\begin{array}{l}\text { Singh and Bali } \\
2015[53]\end{array}$ \\
\hline $\begin{array}{l}\text { The relation stability } \\
\text { is the basis for } \\
\text { selecting the next } \\
\text { transmission node } \\
\text { and a greedy } \\
\text { algorithm for data } \\
\text { transfer }\end{array}$ & $\begin{array}{l}\text { Smart, secure and reliable } \\
\text { data distribution protocol } \\
\text { focused on transmission }\end{array}$ & Urban & NS-3 & $\begin{array}{l}\text { The suggested program is best for } \\
\text { PDR and efficiency, with a small } \\
\text { latency increase }\end{array}$ & $\begin{array}{l}\text { Chahal et al. } \\
2019 \text { [54] }\end{array}$ \\
\hline $\begin{array}{l}\text { Selection of hybrid } \\
\text { relay nodes which } \\
\text { attempts to leverage } \\
\text { the best } \\
\text { characteristics of } \\
\text { established messages }\end{array}$ & $\begin{array}{l}\text { Accessibility of } \\
\text { communications, contact } \\
\text { time and the usage of } \\
\text { bandwidth eliminating any } \\
\text { limitation }\end{array}$ & Highway & NS2 & $\begin{array}{l}\text { The process is better than } \\
\text { traditional approaches }\end{array}$ & $\begin{array}{l}\text { Osama et al. } \\
2019[55]\end{array}$ \\
\hline $\begin{array}{l}\text { Stability of the } \\
\text { relation determined } \\
\text { in the Euclidean } \\
\text { polar system by } \\
\text { distance }\end{array}$ & $\begin{array}{l}\text { A modern DPSO } \\
\text { algorithm with meta- } \\
\text { heuristic interest. }\end{array}$ & Urban & NS-3 & $\begin{array}{l}\text { The suggested solution is stronger } \\
\text { relative to certain criteria found } \\
\text { than the other protocol }\end{array}$ & $\begin{array}{l}\text { Manisha et al. } \\
2019[56]\end{array}$ \\
\hline $\begin{array}{l}\text { A time limit system } \\
\text { for raising } \\
\text { communication } \\
\text { overhead }\end{array}$ & $\begin{array}{l}\text { Technique to reduce the } \\
\text { overhead of } \\
\text { communications utilizing } \\
\text { a time constraint method }\end{array}$ & Urban & NS-3 & $\begin{array}{l}\text { Latest approach aims to minimize } \\
\text { pollution by broadcasting }\end{array}$ & $\begin{array}{l}\text { Shah et al. } \\
2019 \text { [57] }\end{array}$ \\
\hline $\begin{array}{l}\text { Effective clustering } \\
\text { scheme (MPECS) } \\
\text { dependent on } \\
\text { mobility prediction }\end{array}$ & $\begin{array}{l}\text { MPECS is recommended } \\
\text { for enhancing VANETs' } \\
\text { performance. }\end{array}$ & Urban & NS2 & $\begin{array}{l}\text { Current strategy aims to reduce } \\
\text { pollution by transmission } \\
\text { networks }\end{array}$ & $\begin{array}{l}\text { Tharwat et al. } \\
2019 \text { [58] }\end{array}$ \\
\hline $\begin{array}{l}\text { Scheme for the } \\
\text { provision of data on } \\
\text { clustering and likely } \\
\text { broadcasting }(\mathrm{CPB})\end{array}$ & $\begin{array}{l}\text { Clustering guidance and } \\
\text { probabilistic radio } \\
\text { programming }\end{array}$ & Urban & NS2 & $\begin{array}{l}\text { Enhanced packet transmission } \\
\text { efficiency, knowledge } \\
\text { distribution and average time to } \\
\text { transmit. }\end{array}$ & $\begin{array}{l}\text { Liu et al. } 2018 \\
\text { [59] }\end{array}$ \\
\hline
\end{tabular}




\section{REFERENCES}

[1] Department of Statistics Malaysia, "Compendium of environment statistics," Percetakan Nasional Malaysia Bhd., Malaysia, Putrajaya 2006.

[2] N. M. Shariff, "Private Vehicle Ownership and Transportation Planning in Malaysia," International Conference on Traffic and Transportation Engineering (ICTTE 2012), vol. 26, pp. 64-68, 2012.

[3] O. S. Al-heety, et al., "A comprehensive survey: Benefits, Services, Recent works, Challenges, Security and Use cases for SDN-VANET,” IEEE Access, vol. 8, pp. 1-20, 2020.

[4] Y. Yang and R. Bagrodia, "Evaluation of VANET-based advanced intelligent transportation systems," in Proceedings of the Sixth ACM International Workshop on Vehicular Internetworking, New York, NY, USA, pp. 3-12, 2009.

[5] M. Paolucci and R. Sacile, "Agent-Based Manufacturing and Control Systems," CRC Press, Florida, United State of America, 2004.

[6] A. C. Baktir, et al., "How Can Edge Computing Benefit from Software-Defined Networking: A Survey, Use Cases, and Future Directions," IEEE Communications Surveys \& Tutorials, vol. 19, no. 4, pp. 2359-2391, 2017.

[7] M. A. Saad, et al., "Performance evaluation improvement of energy consumption in adhoc wireless network," International Journal of Advanced Science and Technology, vol. 29, no. 3, pp. 4128-4137, 2020.

[8] A. M. Fahad, et al., "Ns2 based performance comparison study between dsr and aodv protocols," International Journal of Advanced Trends in Computer Science and Engineering, vol. 8, no. 1.4, pp. 379-393, 2019.

[9] S. Alani, et al., "A new energy consumption technique for mobile Ad-Hoc networks," International Journal of Electrical and Computer Engineering (IJECE), vol. 9, no. 5, pp. 4147-4153, 2019.

[10] S. A. Rashid, et al., "Prediction based efficient multi-hop clustering approach with adaptive relay node selection for VANET," Journal of Communications, vol. 15, no. 4, pp. 332-344, 2020.

[11] S. A. Hussein and D. P. Dahnil, "A New Hybrid Technique to Improve the Path Selection in Reducing Energy Consumption in Mobile AD-HOC Networks," International Journal of Applied Engineering Research, vol. 12, no. 3, pp. 277-282, 2017.

[12] R. A. Santos, et al., "Performance evaluation of routing Protocols in Vehicular Ad Hoc Networks," The International Journal of Ad Hoc and Ubiquitous Computing, vol. 1, no. 1, pp. 80-91, 2005.

[13] M. Ayaida, et al., "Improving the link lifetime in VANETs," Proceedings of IEEE 36th Conference on Local Computer Networks (LCN), pp. 905-912, 2011.

[14] J. Blum, et al., "Mobility Management in IVC Networks," in Proceedings of IEEE Intelligent Vehicles Symposium, pp. 150-155, 2003.

[15] M. M. Hamdi, et al., "A Survey on Data Dissemination and Routing Protocol in VANET: Types, Challenges, opportunistic and Future Role," International Journal of Advanced Science and Technology, vol. 29, no. 5, pp. 6473-6482, 2020

[16] E. M. Royer and C. E. Perkins, "Multicast Ad hoc On-demand Distance Vector (MAODV) Routing," Internet Draft. [Online]. Available: http://tools.ietf.org/html/draft-ietf-manet-maodv-00.

[17] L. Huang et al., "Efficient Data Traffic Forwarding for Infrastructure-to-Infrastructure Communications in VANETs," IEEE Transactions on Intelligent Transportation Systems, vol. 19, no. 3, pp. 839-853, 2018.

[18] C. J. Joshua and V. Varadarajan, "An optimization framework for routing protocols in vanets: a multi-objective firefly algorithm approach," Wireless Networks, pp. 1-10, 2019.

[19] H. G. V. Andrade, et al., "Multi-objective approaches to improve QoS in vehicular ad-hoc networks," Proceedings of the 8th ACM Symposium on Design and Analysis of Intelligent Vehicular Networks and Applications, pp. 41-48, 2018.

[20] U. Mohanakrishnan and B. Ramakrishnan, "MCTRP: An Energy Efficient Tree Routing Protocol for Vehicular Ad Hoc Network Using Genetic Whale Optimization Algorithm,” Wireless Personal Communications, vol. 110, no. 1, pp. 185-206, 2020.

[21] Q. Yang, et al., "ACAR: Adaptive Connectivity Aware Routing for Vehicular Ad Hoc Networks in City Scenarios," Mobile Networks and Applications, vol. 15, no. 1, pp. 36-60, 2010.

[22] M. Eusuff, et al., "Shuffled frog-leaping algorithm: A memetic meta-heuristic for discrete optimization," Engineering Optimization, vol. 38, no. 2, pp. 129-154, 2006.

[23] V. Krundyshev, et al., "Artificial swarm algorithm for VANET protection against routing attacks," Proc. 2018 IEEE Industrial Cyber-Physical Systems (ICPS 2018), pp. 795-800, 2018.

[24] G. Zhang, et al., "Genetic Algorithm Based QoS Perception Routing Protocol for VANETs," Wireless Communications and Mobile Computing, vol. 2018, pp. 1-11, 2018.

[25] H. Bello-Salau, et al., "An optimized routing algorithm for vehicle ad-hoc networks," Engineering Science and Technology, an International Journal, vol. 22, no. 3, pp. 754-766, 2019.

[26] X. Zhang, et al., "A micro-artificial bee colony based multi-cast routing in vehicular ad hoc networks," Ad Hoc Networks, vol. 58, pp. 213-221, 2017.

[27] M. Elhoseny, "Intelligent firefly-based algorithm with Levy distribution (FF-L) for multi-cast routing in vehicular communications," Expert Systems with Applications, vol. 140, 2020.

[28] J. J. Mulcahy, et al., "Autonomic computing and VANET," SoutheastCon, pp. 1-7, 2015.

[29] F. Arena and G. Pau, "An Overview of Vehicular Communications," Future Internet, vol. 11, no. 2, pp. 27-38, 2019. 
[30] F. Li and Y. Wang, "Routing in vehicular ad hoc networks: A survey," IEEE Vehicular technology magazine, vol. 2, no. 2, pp. 12-22, 2007.

[31] R. S. Schwartz, et al., "A directional data dissemination protocol for vehicular environments," Computer Communications, vol. 34, no. 17, pp. 2057-2071, 2011.

[32] $\mathrm{C}$. $\mathrm{Wu}$, et al., "A low latency path diversity mechanism for sender- oriented broadcast protocols in VANETs," Ad Hoc Networks, vol. 11, no. 7, pp. 2059-2068, 2013.

[33] W. Abdou, et al., "Using an evolutionary algorithm to optimize the broadcasting methods in mobile ad hoc networks," Journal of Network and Computer Applications, vol. 34, no. 6, pp. 1794-1804, 2011.

[34] S. Alani, et al., "A Study Review on Mobile Ad-Hoc Network: Characteristics, Applications, Challenges and Routing Protocols Classification," International Journal of Advanced Science and Technology, vol. 28, no. 1, pp. 394-405, 2019.

[35] F. G. Mármol and G. M. Pérez, "TRIP, a trust and reputation infrastructure-based proposal for vehicular ad hoc networks," Journal of Network and Computer Applications, vol. 35, no. 3, pp. 934-941, 2012.

[36] W. Alasmary and W. Zhuang, "Mobility impact in IEEE 802.11p infrastructureless vehicular networks," Ad Hoc Networks, vol. 10, no. 2, pp. 222-230, 2012.

[37] L. Maglaras, et al., "Social Aspect of Vehicular Communications," EAI Transactions on Cloud Systems, vol. 1, no. 1 , pp. 1-10, 2015

[38] B. Khorashadi, et al., "Distributed automated incident detection with VGRID," IEEE Wireless Communications, vol. 18, no. 1, pp. 64-73, 2011.

[39] V. Naumov and T. R. Gross, "Connectivity-Aware Routing (CAR) in Vehicular Ad-hoc Networks," in IEEE International Conference on Computer Communications (INFOCOM 2007), pp. 1919-1927, 2007.

[40] O. A. Wahab, et al., "VANET QoS-OLSR: QoS- based clustering protocol for vehicular ad hoc networks," Computer Communications, vol. 36, no. 13, pp. 1422-1435, 2013.

[41] R. Akamatsu, et al., "Adaptive delay-based geocast protocol for data dissemination in urban VANET," in 2014 Seventh International Conference on Mobile Computing and Ubiquitous Networking, pp. 141-146, 2014.

[42] P. Salvo, et al., "Timer based distributed dissemination protocols for VANETs and their interaction with MAC layer," in IEEE 77th Vehicular Technology Conference, pp. 1-6, 2013.

[43] A. Baiocchi, et al., "Understanding spurious message forwarding in vanet beaconless dissemination protocols: An analytical approach," IEEE Transactions on Vehicular Technology, vol. 65, no. 4, pp. 2243-2258, 2016.

[44] N. Wisitpongphan, et al., "Broadcast storm mitigation techniques in vehicular ad hoc networks," IEEE Wireless Communications, vol. 14, no. 6, pp. 84-94, 2007.

[45] O. K. Tonguz, et al., "DV-CAST: A distributed vehicular broadcast protocol for vehicular ad hoc networks," IEEE Wireless Communications, vol. 17, no. 2, pp. 47-57, 2010.

[46] S. Panichpapiboon and L. Cheng, "Irresponsible forwarding under real intervehicle spacing distributions," IEEE Transactions on Vehicular Technology, vol. 62, no. 5, pp. 2264-2272, 2013.

[47] A. Mostafa, et al., "A probabilistic routing by using multi-hop retransmission forecast with packet collision-aware constraints in vehicular networks," Ad Hoc Networks, vol. 14, no. 3, pp. 118-129, 2014.

[48] A. Mondal and S. Mitra, "Secure data dissemination in VANET - a pull based approach," in IEEE International Conference on Communication, Networks and Satellite, pp. 60-67, 2016.

[49] S. Bai, et al., "Vehicular multi-hop broadcasting protocol for safety message dissemination in VANETs," in IEEE 70th Vehicular Technology Conference Fall, pp. 1-5, 2009.

[50] A. Lakas and M. Shaqfa, "Geocache: Sharing and exchanging road traffic information using peer-to-peer vehicular communication," in Vehicular Technology Conference, pp. 1-7, 2011.

[51] L. Zhang, et al., "Smartgeocast: Dynamic abnormal traffic information dissemination to multiple regions in VANET," in Wireless Communications and Mobile Computing Conference, pp. 1750-1755, 2013.

[52] J. P. Singh and R. S. Bali, "A hybrid backbone-based clustering algorithm for vehicular ad-hoc networks," Procedia Computer Science, vol. 46, pp. 1005-1013, 2015.

[53] B. Hassanabadi, et al., "Clustering in vehicular ad hoc networks using affinity propagation," Ad Hoc Networks, vol. 13, no. 1, pp. 535-548, 2014.

[54] D. Jin, et al., "Cluster based emergency message dissemination scheme for vehicular ad hoc networks," in International Conference on Ubiquitous Information Management and Communication, pp. 1-8, 2015.

[55] M. Chahal and S. Harit, "A stable and reliable data dissemination scheme based on intelligent forwarding in VANETs," International Journal of Communication Systems, vol. 32, no. 3, 2019.

[56] O. Rehman and M. Ould-Khaoua, "A hybrid relay node selection scheme for message dissemination in VANETs," Future Generation Computer Systems, vol. 93, pp. 1-17, 2019.

[57] S. S. Shah, et al., "Time Barrier-Based Emergency Message Dissemination in Vehicular Ad-hoc Networks," in IEEE Access, vol. 7, pp. 16494-16503, 2019.

[58] I. T. Abdel-Halim, et al., "Mobility prediction-based efficient clustering scheme for connected and automated vehicles in VANETs," Computer Networks, vol. 150, pp. 217-233, 2019.

[59] L. Liu, et al., "A data dissemination scheme based on clustering and probabilistic broadcasting in VANETs," Vehicular Communications, vol. 13, pp. 78-88, 2018. 


\section{BIOGRAPHIES OF AUTHORS}
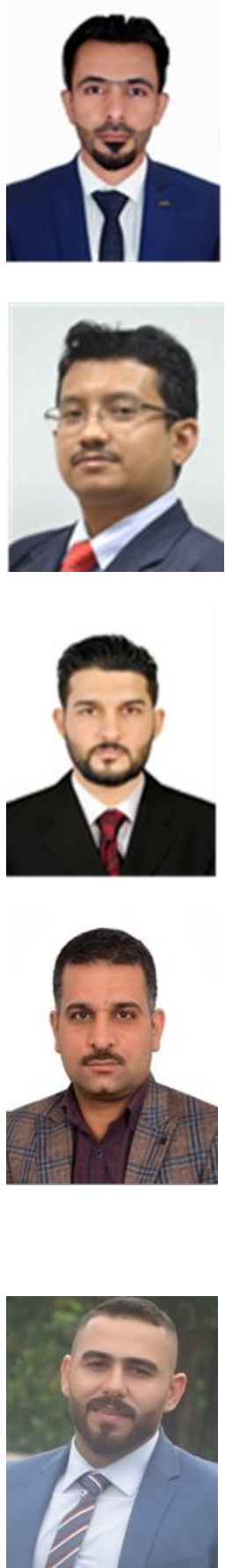

Sami Abduljabbar Rashid was born in Al-Anbar, Iraq. He received the B.Eng. Degree in computer engineering technology from Al-Maarif University College, Iraq and the M.Sc. degree in communication and computer engineering from University Kebangsaan Malaysia (UKM), Malaysia. He is currently pursuing the Ph.D. degree in the department of communication engineering, University Tun Hussein Onn Malaysia (UTHM), Malaysia. His research interests include wireless and mobile communications and VANET.

Lukman Audah was born in Kuala Lumpur, Malaysia. He received the B.Eng. Degree in telecommunications from Universiti Teknologi Malaysia, in 2005, and the M.Sc. degree in communication networks and software and the Ph.D. degree in electronic engineering from the university of Surrey, U.K. He is currently a lecturer with the communication engineering Department, University Tun Hussein Onn Malaysia. His research interests include wireless and mobile communications, Internet traffic engineering, network system management, data security, and satellite communication.

Mustafa Maad Hamdi was born in Al-Anbar, Iraq. He received the B.Eng. Degree in Computer Engineering Technology from Al-Maarif University College, Iraq and the M.Sc. degree in Communication and Computer Engineering from University Kebangsaan Malaysia (UKM), Malaysia. $\mathrm{He}$ is currently pursuing the $\mathrm{Ph} . \mathrm{D}$. degree in the department of communication engineering, University Tun Hussein Onn Malaysia (UTHM), Malaysia. His research interests include Wireless and Mobile Communications, VANET, MANET, Satellite Communication, and Cryptographic.

Mohammed Salah Abood was born in Baghdad, Iraq on 5th Dec. 1981, received the BSc degree in computer engineering from University of Technology, Baghdad-Iraq, in 2004, and the master's degree in communication and computer engineering, University Kebangsaan Malaysia (UKM), Malaysia, in 2016. He is currently studying toward the $\mathrm{PhD}$ degree in the field of information and communication engineering in Beijing Institute of Technology (BIT), Beijing-China, starting on 2019. He is worked as a director of the research division of the directorate of information systems, MoD-Iraq. His current research interests include, network function virtualization, future mobile packet core networks, open source networking, internet of things (IoT) especially as the world is heading towards the 5G networking, software-defined network (SDN), radio access technologies, cyber security, cryptography, and mobile communication. Finally, I believe in teamwork, open communication, and growth through the strengths of others.

Sameer Alani was born in Iraq, in 1989. He received the B.S. degree in computer engineering and the M.Sc. degree in wireless communication and Computer networking technology from The National University of Malaysia (UKM), in 2017. He is currently pursuing the Ph.D. degree in wireless communication and networking. His research interests include antenna applications, SDN, VANET, wireless communication, and networking technology. 